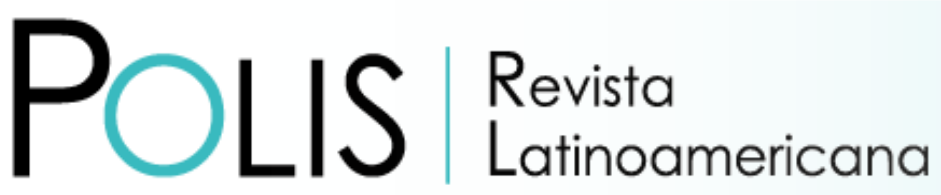

V20 | N58 | 2021

DOI: $10.32735 /$ S0718-6568/2021-N58-1580

\title{
Conocer, comprender, intervenir. La ética de la alteridad y los aportes del conocimiento antropológico a la formación de profesionales del trabajo social ${ }^{1}$
}

\author{
Roberto Álvarez San Martín \\ Universidad Santo Tomás e Instituto Profesional Santo Tomás, Temuco, Chile. \\ Email: robertoalvarez@santotomas.cl
}

Recibido: 09.03.2020 | Aceptado: 17.06.2020

\begin{abstract}
Resumen: En el contexto actual la formación en Trabajo Social incorpora la enseñanza de Antropología, donde la pregunta sobre qué se aprende al estudiar Antropología es frecuente. El objetivo de este trabajo es situar, desde la ética de la alteridad, los aportes conceptuales y metodológicos de la Antropología al Trabajo Social. Para ello, la práctica reflexiva docente y la reflexividad antropológica se complementan con una revisión de la producción académica iberoamericana sobre Antropología y Trabajo Social. Teniendo como eje articulador de la reflexión el paradigma de la alteridad, se revisan las concepciones de identidad cultural, etnocentrismo, diversidad cultural y aculturación, mientras que desde lo metodológico se hace referencia al método etnográfico en cuanto herramienta de producción de conocimientos para la intervención social. Se concluye planteando un conjunto de desafíos para antropólogos/as involucrados en procesos formativos en Trabajo Social.
\end{abstract}

Palabras clave: Alteridad; conocimiento cultural; etnografía; formación en Trabajo Social.

\section{To Know, Understand and Intervene. The Ethics of Alterity and the Contribu- tions of Anthropological Knowledge in Training Social Workers}

\begin{abstract}
In the current context, training in Social Work incorporates teaching Anthropology, where a frequente query is related to what is learned by studying Anthropology. The objective of this work is to locate, from the ethics of alterity, the conceptual and methodological contributions of Anthropology to Social Work. To do this, reflective teaching practice and anthropological reflexivity are complemented by a review of the lbero-American academic production on anthropology and social work. Taking the paradigm of alterity as the articulating axis of reflection, the article reviews the conceptions of cultural identity, ethnocentrism, cultural diversity and acculturation; while from the methodological point of view the ethnographic method is refered to as a knowledge production tool for social intervention. It concludes by posing a set of challenges for anthropologists involved in training processes in Social Work.
\end{abstract}

Keywords: Alterity; cultural knowledge; ethnography; Social Work training.

\footnotetext{
1 Una versión preliminar de este artículo fue presentada en el III Congreso Internacional de Trabajo Social, "Tensiones ético políticas de la formación y práctica disciplinar del trabajo social. Rupturas y consensos de las hegemonías en América Latina", Red de Escuelas de Trabajo Social del Consejo de Rectores de Universidades Chilenas, 8, 9 y 10 de octubre de 2019, Temuco, Chile.
} 


\section{Conhecer, entender, intervir. A ética da alteridade e as contribuições do conhecimento antropológico para a formação de profissionais de Serviço Social}

Resumo: No contexto atual, a formação em Serviço Social incorpora o ensino da Antropologia, onde a pergunta sobre o que é aprendido pelo estudo da Antropologia é frequente. O objetivo deste trabalho é localizar, a partir da ética da alteridade, as contribuições conceituais e metodológicas da Antropologia para o Trabalho Social. Para isso, a prática pedagógica reflexiva e a reflexividade antropológica são complementadas por uma revisão da produção acadêmica ibero-americana de Antropologia e Trabalho Social. Tomando o paradigma da alteridade como eixo articulador da reflexão, são revisadas as concepções de identidade cultural, etnocentrismo, diversidade cultural e aculturação, enquanto do ponto de vista metodológico o método etnográfico é referenciado como uma ferramenta de produção de conhecimento para a intervenção social. Conclui-se colocando um conjunto de desafios para os antropólogos envolvidos nos processos de treinamento em Serviço Social.

Palavras-chave: Alteridade; conhecimento cultural; etnografia; treinamento de Trabalho Social.

\section{Cómo citar este artículo:}

Álvarez San Martín, R. (2021). Conocer, comprender, intervenir. La ética de la alteridad y los aportes del conocimiento antropológico a la formación de profesionales del trabajo social. Polis Revista Latinoamericana, 20 (58), 104-1 19. doi: http://dx.doi.org/10.32735/S07186568/2021-N58-1580

\section{Introducción}

El Trabajo Social latinoamericano durante las primeras décadas del siglo XXI se ha enfrentado al cuestionamiento de si se trata de una disciplina o una profesión, a pesar de que en otras latitudes no hay duda de que se está ante una disciplina y una profesión (Barahona, 2016) toda vez que desde sus orígenes ha mantenido un vínculo permanente entre teoría y práctica, entre la generación de conocimiento disciplinar y la intervención social.

Sin embargo, en América Latina persiste la pregunta ¿̇Disciplina o profesión? Así, cuando un profesional de Trabajo Social "frente a la demanda de los usuarios utiliza un conjunto de teorías (conocimientos), para explicar y/o comprender la situación problema que ha llevado al usuario a requerir sus servicios profesionales (...) [para brindar] una solución pertinente a la demanda" (Farías, 2012, p.50-51), se encontraría en la dimensión profesional. Si, por el contrario, ese profesional "hace una reconstrucción racional de los procedimientos que ha efectuado tras un proceso de intervención social exitoso, y plantea una modelización del mismo" (Farías, 2012, p.51), se situaría en la dimensión disciplinar.

Este asunto, desde la perspectiva que este trabajo plantea, ha estado y sigue estando presente en los itinerarios formativos que se construyen en torno al Trabajo Social. Se observa 
un denominador común: en el centro del proceso formativo se ubica el concepto de intervención social y, junto a él, se transmite, enseña y aprende un conjunto de herramientas teóricas, conceptuales y prácticas orientadas a "dar curso a respuestas para los problemas, necesidades y demandas sociales de individuos, grupos, barrios, comunidades" (País, Girola y Thomasz, 2016, p.1), familias y organizaciones, situando el énfasis formativo en el ámbito de lo profesional.

La actual formación de profesionales en Trabajo Social se sitúa en un escenario social complejo. Por un lado, hay un mundo laboral en movimiento, flexible y precario; una sociedad pluricultural en construcción permanente e inacabada; en lo político, conviven las formas tradicionales y conservadoras con el descontento y desencanto social y cultural de nuevas generaciones; en lo ciudadano, se observa un movimiento social desestructurado y fragmentado en luchas y discursos desde el margen. Por otro lado, está la complejidad propia del estudiantado; las aulas cada año siguen recibiendo jóvenes que son primera generación en educación superior, millennials, centennials y prosumidores.

En este escenario las mallas curriculares para los futuros profesionales del Trabajo Social se orientan hacia la formación por competencias para la intervención, especialistas en el hacer (Carballeda, 2008), para lo cual los procesos académicos se caracterizan por una amplia formación teórico-práctica para la transformación social, por lo que se incorporan asignaturas propias de la profesión así como del ámbito de las ciencias económicas y administrativas, jurídicas y sociales, entre las cuales se sitúa la Antropología.

En el caso de esta última, la mayor parte de las instituciones de educación superior que en Chile incorporan Antropología en el currículo de Trabajo Social², la ubican como una asignatura de formación general, tributando al desarrollo de competencias vinculadas al saber hacer: saber diagnosticar un problema, saber diseñar una intervención social, saber implementarla, saber evaluarla.

El presente artículo, ante la escasa producción académica nacional sobre el vínculo entre la Antropología y el Trabajo Social, tiene como objetivo representar una contribución a la reflexión sobre el aporte de la formación antropológica en futuros profesionales del Trabajo Social. En particular, el eje vertebrador de esta reflexión está dado por las aportaciones éticas de la conceptualización sobre la alteridad y su inclusión en intervenciones sociales desde el Trabajo Social, a partir de la cual se estructuran otros aportes disciplinares tanto en lo conceptual como en lo metodológico.

2 El primer semestre de 2019, de 35 universidades chilenas que dictaban la carrera, el 77\% incluía la asignatura de Antropología. 


\section{Antropología en el aula: ¿Enseñarla o aprenderla?}

Algunos clásicos de la Antropología han expresado su interés por los problemas que representa su enseñanza. A mediados de la década de 1950, Claude Lévi-Strauss planteaba la preocupación acerca de qué se enseña cuando se enseña Antropología, se preguntaba si acaso "se habla simplemente de antropología, o bien de antropología cultural y hasta de etnología, de etnografía, de tradiciones populares" (Lévi-Strauss, 1995, p.359). Poco después, el británico Raymond Firth, enfatizaba que la enseñanza de la Antropología tiene como tarea principal desarrollar "la capacidad del alumno para pensar por sí mismo, de seguir las implicaciones de generalizaciones existentes, de discutir y criticar puntos de vista aceptados, incluyendo los de su maestro" (Firth, 1965 citado en Amilibia, 2017, p.37).

El pensar acerca de la enseñanza de la Antropología y los aprendizajes que aporta, más allá de la posición de autores clásicos, ha cobrado cierto ímpetu en la última década. Recientemente, Fabrizio y Gallardo (2016) se cuestionan sobre las características del estudiantado y las materias disciplinares que para enseñar de manera situada: hay que conocer a quiénes se enseñará y en qué contexto; Brunatti et al. (2016) analizan el papel que le cabe al trabajo de campo etnográfico en la enseñanza del oficio antropológico; Ortiz (2016) y Mancera y Romero (2017) reflexionan sobre los retos y desafíos de la enseñanza de la Antropología en contextos de diversidad cultural en Latinoamérica; Cerletti (2017) plantea cuestiones asociadas a la articulación necesaria entre investigación y enseñanza de la Antropología, así como de la incorporación de la etnografía en los procesos de enseñanza; Ortale (2018) releva el aporte de la Antropología, por medio de la observación y escucha, hacia la comprensión del otro.

A partir de lo anterior, pareciera ser que la mirada de Lévi-Strauss centrada en la enseñanza (el maestro), vuelve a interpelar a los enseñantes de Antropología, dejando pendiente el énfasis planteado por Firth, quien se interesa en el aprendizaje (el estudiante), cuestión central en el actual modelo educativo en las universidades chilenas que adscriben a la formación basada en competencias. Entonces, con el foco puesto en los estudiantes, cabe preguntarse ¿Qué se aprende cuando se estudia Antropología?

Krotz (2012) identifica tres clases de aprendizaje que se pueden lograr al estudiar Antropología. Entre los primeros están aquellos relacionados con el trabajo de campo, se comienza a aprender a buscar información mediante la observación etnográfica, se amplía el vocabulario con lenguaje técnico, se realiza una aproximación inicial a "instrumentos cognitivos relativamente especializados para generar y sistematizar información etnográfica de primera y segunda mano, y para analizarla" (Krołz, 2012, p.5) y se aprende a comunicar los resultados. El uso de este recurso de aprendizaje se encuentra documentado en Alcázar y Espinosa (2014), Silva, Sacramento y Mendonça (2015), Artiñano, Bergé, García y Gómez (2017), Cerletti (2017) y Ortale (2018), entre otros. 
Un segundo grupo de aprendizajes, corresponde al desarrollo de habilidades intelectuales y científicas generales. Aquí están la capacidad de realizar búsquedas bibliográficas y documentales, la familiarización con la lectura de "textos relativamente largos y complejos" (Krotz, 2012, p.5) y el tránsito desde el trabajo en grupo hacia el trabajo en equipo. En este ámbito, Mijangos y Ambrocio (2013) dan cuenta del uso de la Antropología en la alfabetización académica de estudiantes de pregrado.

El tercer grupo de aprendizajes se sitúa exclusivamente en el estudiante y su historia personal. Tal vez los impactos más relevantes se encuentran en este nivel, pues aquí comienza a quedar en evidencia que al aprendizaje de Antropología le acompaña el cuestionamiento de las verdades y certezas adquiridas durante la infancia y adolescencia, lo cual deviene en un proceso de re-aprendizaje de la historia personal, familiar e incluso social; es lo que Sepúlveda ha definido como la "búsqueda histórica de comprender por qué las situaciones, fenómenos o cosas son como son y no de otra manera" (2001, p.5). Incluso, en palabras de Ortale (2018), "los alumnos rescatan la posibilidad de haber cuestionado el propio sentido común y logrado descentrarse de sus referentes culturales, revisar la propia percepción del mundo y reconocer prejuicios" (2018, p.50). Por otra parte, hay también un impacto en la socialización política, pues el acceso a la educación superior suele coincidir con una etapa del ciclo vital en la que se está alcanzando una ciudadanía con derechos plenos; también se comienza a aprender que una misma situación social o cultural puede ser vista desde diferentes perspectivas.

\section{Metodología}

En términos metodológicos, este artículo se sustenta en un paradigma crítico reflexivo, articulando la práctica reflexiva para docentes (Domingo, 2013) y la reflexividad antropológica (Bourdieu y Wacquant, 1995). Este trabajo nace de la motivación e interés de su autor, ante la escasez de producción académica nacional sobre los vínculos entre Antropología y Trabajo Social, y la experiencia docente en el campo de la Antropología a estudiantes de Trabajo Social.

Planteado así, este artículo debe ser considerado el punto de partida e inacabado de un estado del arte sobre los aportes de la Antropología a la formación de profesionales del Trabajo Social, por una parte, y la reflexión sobre la propia práctica docente de Antropología en una escuela de Trabajo Social en una institución de educación superior chilena, por otra. Para el primer caso - un estado del arte en construcción - se consultaron fuentes bibliográficas provenientes de lberoamérica, en donde destaca la producción académica en Argentina, seguida por España e, incipientemente, publicaciones realizadas en Portugal, Uruguay, Venezuela, El Salvador, Brasil, México y Chile. 
Para el proceso (auto)reflexivo se ha recurrido a la revisión de notas de campo tomadas en el curso de la dictación de la asignatura de Antropología, y el reporte de estudiantes que han cursado la cátedra entre los años 2015 y 2019.

\section{La ética de la alteridad}

Cuando Mary Richmond escribió el clásico libro Diagnóstico Social, lo hizo pensando en la profesionalización y cientificidad para el Trabajo Social. Bastaba con conocer al usuario mediante el diagnóstico e intervenir según ese conocimiento (Idareta, 2011), quedando reducido a un sujeto-pasivo-receptor de la acción profesional (Zárate, 2016). Esta práctica, desprovista de la dimensión humana, tan necesaria para la comprensión de la humanidad, generó una crisis de lo humano en el Trabajo Social caracterizada por una relación vertical "entre el trabajador social y la persona, la que se ha visto revestida tradicionalmente de una suerte de paternalismo y autoritarismo que no ha hecho otra cosa más que vulnerar el valor y respeto hacia el ser humano" (Zárate, 2016, p.167).

Sin embargo, el dilema que genera trabajar con humanos sin considerar su humanidad comienza a ser asumido desde la Antropología a través de la categoría analítica de otro.

" Quiero hablar del descubrimiento que el yo hace del otro. El tema es inmenso. Apenas lo fórmula uno en su generalidad, ve que se subdivide en categorías y en direcciones múltiples, infinitas. Uno puede descubrir a los otros en uno mismo, darse cuenta de que no somos una sustancia homogénea, y radicalmente extraña a todo lo que no es uno mismo: yo es otro. Pero los otros también son yos: sujetos como yo, que sólo mi punto de vista, para el cual todos están allí y sólo yo estoy aquí, separa y distingue verdaderamente de mí. Puedo concebir a esos otros como una abstracción, como una instancia de la configuración psíquica de todo individuo, como el Otro, el otro y otro en relación con yo; o bien como un grupo social concreto al que nosotros no pertenecemos. Ese grupo puede, a su vez, estar en el interior de la sociedad (...); o puede ser exterior a ella, es decir, otra sociedad, que será, según los casos, cercana o lejana: seres que todo acerca a nosotros en el plano cultural, moral, histórico; o bien desconocidos, extranjeros cuya lengua y costumbres no entiendo, tan extranjeros que, en el caso límite, dudo en reconocer nuestra pertenencia común a una misma especie". (Todorov, 1998, p.13)

Ese otro al que hace referencia Todorov es la humanidad que, al ser culturalmente diversa, es también única en su condición humana, lo cual implica reconocer al otro diferente como un igual. Desde esta perspectiva, "la principal aportación ética que ofrece la antropología [al Trabajo Social] es saber reconocer, comprender y respetar la diversidad humana" (Fernández, 2012, p.19); reconocer, comprender y respetar a los otros, aquellos que en el pasado antropológico eran las sociedades exóticas y que en el presente, son los otros sociales o culturales que habitan en barrios, comunidades y organizaciones, son otros más próximos y cercanos "geográficamente pero lejano[s] en términos de distancia social" (Amilibia, Colangelo, Danel, Rodríguez y Tello, 2015, p.16).

Al respecto, Fombuena-Valero (2011) pregunta ¿QQuién es el otro del Trabajo Social? La respuesta se encuentra en la concepción de alteridad que, si bien refiere a la diferenciación, 
es más que una simple y sencilla diferenciación, pues expresa una relación dialógica entre el yo y el tú, que conduce al reconocimiento del otro en la diferencia, se trata del reconocimiento del otro distinto como "un ser en relación, que existe en presencia de otro, construyendo una realidad que se fundamenta en la autenticidad [convirtiendo al tú] en otro, a la vez extraño y parecido" (Fombuena-Valero, 201 1, p.63). Esta perspectiva demanda del profesional del Trabajo Social avanzar desde la búsqueda de resultados objetivables y medibles en la intervención hacia una lógica de encuentro y diálogo entre diferentes e iguales a la vez. Sin embargo, este ejercicio cognitivo de la construcción del otro en Trabajo Social, cualquiera sea el contenido de ese otro, "condiciona en parte el tipo de trabajo social que se desempeña" (Solana, 2002, p.147) y demanda del trabajador social un encuentro cara a cara con el otro, en cuya relación dialógica "todo supone partir de sus propios modos de nombrar y nombrarse" (Baldoni y Fontana, 2016) a ese otro.

Desde la lógica de la reflexividad, la ética de la alteridad conduce al trabajador social a ampliar y profundizar el conocimiento sobre sí mismo (Krotz, 1994) y sobre la intervención social profesional, así como a tomar conciencia que ninguna de sus intervenciones se produce en el vacío, pues cada una de sus actuaciones está cargada de sentidos para el yo y para el tú; y habrá entonces que descubrir y comprender el sentido de la intervención para el trabajador social y el sentido de la intervención para el intervenido.

El valor de la ética de la alteridad en la intervención social queda de manifiesto en un estudio realizado en Chile por Castro-Serrano, Reininger, Flotts, Vergara y Fuentealba (2016) acerca de las políticas de transferencias monetarias como estrategia para afrontar la pobreza. Al comparar el Programa Puente y el Ingreso Ético Familiar (IEF), los investigadores relevan que el hecho de que el Programa Puente contara con la figura del apoyo familiar - habitualmente un trabajador social - favoreció un abordaje multidimensional de la pobreza, pues el foco estaba puesto en "acompañar a las familias en su proceso de desarrollo y superación de tal condición" (Castro-Serrano et al., 2016, p.40), cuestión muy bien valorada cualitativamente, las familias eran el motor (protagonistas) de su propio desarrollo y mejora de sus condiciones socioeconómicas; no cabe duda que en la base de esta política estatal ejecutada por profesionales de Trabajo Social estaba la alteridad como paradigma.

Posteriormente, el Programa Puente es reemplazado por el IEF, el cual se centra en transferencias monetarias y el ingreso de la familia al mercado laboral como estrategia de superación de su precariedad económica, perdiéndose el abordaje multidimensional de la pobreza y produciendo la disgregación del apoyo profesional. Se pasa de un profesional (apoyo familiar del Programa Puente) a tres profesionales que actúan de manera fragmentada y estandarizada con las familias (IEF), sin consideración de las características diferenciadoras de cada una de ellas. "Lo particularmente sensible en esta situación, es la total invisibilización de las familias como sujetos vivos, con voz e injerencia" (Castro-Serrano et al., 2016, p.41), lo cual da cuenta de cómo el IEF carece de una ética de la alteridad, cuestión esencial para transformaciones sociales sustentadas en una relación dialógica y de reconocimiento del otro como protagonista de la mejora en sus condiciones de vida. 
A nivel de las conclusiones, los autores sostienen que si lo que se busca es la superación de condiciones de pobreza, es imperativo que las familias sean protagonistas del proceso, pero conel diseño delIEFse haperdido el encuentro intersubjetivo conel otro, las familias han pasado a ser un beneficiario pasivo y la alteridad ha dejado de ser parte de esta política pública.

\section{Aportes conceptuales de la Antropología}

El antropólogo estadounidense Marvin Harris (1996) ha señalado que uno de los intereses de la Antropología es estudiar las diferencias y semejanzas culturales existentes entre los diversos grupos sociales a fin de acercarse a la comprensión del ser humano. En el nivel conceptual es, quizás, esta afirmación la que sitúa al estudiante de Trabajo Social en su primera aproximación al estudio de la cultura y su expresión en la cotidianidad. Al entender que el concepto de cultura refiere al conjunto de las formas de pensar, sentir y actuar aprendidas y compartidas por los miembros de un grupo social (Harris, 1996), la primera constatación con la que se enfrenta el estudiante es el hecho de reconocer que "todo ser humano es culto en el sentido de que es portador de una u otra cultura" (Linton, 1971, p.44). En la práctica, ello indica al estudiante que más allá del contexto social, cultural, económico, político, histórico, incluso geográfico o territorial, siempre estará en interacción con personas cultas. Ahora bien, una vez que se entiende que la adquisición de la cultura es un proceso continuo y permanente a lo largo de la vida, se comprenderá que ese proceso de aprendizaje cultural tiene efectos o consecuencias sobre la cotidianidad del sujeto: al tiempo que genera identidad, el aprendizaje cultural instala una mirada etnocéntrica, cuestiones necesarias de ser consideradas en toda relación dialógica e intersubjetiva sustentada desde la alteridad.

En cuanto a la identidad cultural, entendida como el sentido de pertenencia a un determinado grupo cultural, resulta interesante comprender que se trata de un concepto múltiple, pues ella es plural, dinámica y dialógica (Conti, 2012). Es plural porque en su construcción confluyen la diversidad de características, intereses, metas y sueños que tiene el individuo, pero también porque "las identidades culturales pueden coexistir y no son mutuamente excluyentes" (Larraín, 2014, p.37). Es dinámica porque está en permanente movimiento, se construye y reconstruye en la historicidad del sujeto; produce "significados e historias con los cuales las personas pueden identificarse" (Larraín, 2014, p.37). Es dialógica porque esa construcción plural y dinámica requiere del diálogo con los otros, con el entorno social, cultural e histórico donde está inserto el sujeto; por tanto, la construcción de identidad cultural - desde la perspectiva que se concibe en este artículo - es consustancial a la ética de la alteridad.

¿Qué tiene que ver esto con la formación de futuros profesionales de Trabajo Social? Estos profesionales habrán de reconocer la identidad cultural de los sujetos en los diversos niveles de intervención social, ya sea que se trate de una familia, un grupo, una comunidad o una organización, incluso si se está ante un individuo en particular (un caso); pues, cualquiera sea el nivel de la intervención, siempre el profesional de Trabajo Social estará 
interactuando con individuos que consideran normal, plausible y con sentido su propio contexto sociocultural. Por lo tanto, el enfoque conceptual de la identidad cultural como constructora de normalidades, plausibilidades y sentidos lleva a reconocer que en la vida social hay diversas normalidades, múltiples plausibilidades y un amplio abanico de sentidos. Antes de intervenir, por lo tanto, el profesional del Trabajo Social debe lograr identificar, describir y comprender esas normalidades, plausibilidades y sentidos, pues "trabajar con una comunidad sin conocer [su cultura] es sencillamente trabajar en el vacío" (Gallego, 2000, p.16).

Hace unos años, una estudiante de Trabajo Social realizando la práctica profesional en un establecimiento de atención primaria de salud del sur de Chile, en el diagnóstico social logró reconocer que los usuarios del centro presentaban diversas identidades culturales (chilena, mapuche, haitiana, venezolana, colombiana, china) y que la atención de salud se realizaba de manera estandarizada, sin consideración de la pertenencia cultural de cada uno de ellos, lo cual generaba que éstos tuvieran una percepción deficiente de la calidad de atención recibida, por una parte, y que el personal de salud no supiera cómo atender de manera diferenciada de acuerdo con las particularidades culturales de los usuarios. La respuesta a este dilema, desde el paradigma de la alteridad, fue el diseño de un programa de formación para el personal del centro, considerando espacios de encuentro e intercambio de conocimientos, experiencias y visiones de mundo con representantes de los usuarios de orígenes culturales diversos. Una situación como ésta, confirma los planteamientos de Raya.Diez, Ezquerro y Serrano-Martínez (2019) sobre la importancia de la gestión de la diversidad cultural por parte de profesionales del Trabajo Social.

Por otra parte, el proceso de aprendizaje cultural conduce a que los sujetos desarrollen una mirada etnocéntrica. El etnocentrismo ha sido definido de diversas formas. La que se adopta aquí es la referida por Chiriguini y Mancusi (2008), al situarlo como una de las variadas expresiones de sociocentrismo que lleva a interpretar el mundo desde la centralidad del grupo social al cual se pertenece, lo que conduce a que los individuos jerarquicen "las culturas y las formas de vida" (Cruz, Ortiz, Yantalema y Orozco, 2018, p.184).

Ahora bien, el centrismo cultural o etnocentrismo:

"consiste en considerar explícita o implícitamente a una cultura (...) como el parámetro general a partir del cual se valoran a las otras culturas. Todo aquello que para una cultura es 'normal', 'éticamente correcto', 'bellamente admirado', (...) pasa a ser la medida general de ponderación de los demás grupos sociales". (Chiriguini y Mancusi, 2008, p.80)

Este aporte conceptual de la Antropología al Trabajo Social demanda de los futuros profesionales un doble ejercicio intelectual y académico. En primer término, el hoy estudiante debe desarrollar la capacidad para reconocer cuáles son los referentes culturales propios que le conducen al establecimiento de vínculos con los sujetos del entorno social inmediato, así como con aquellos que se encuentran más lejanos.

¿Por qué este ejercicio intelectual personal es central en la formación profesional? En la primera parte de este artículo se dijo que al aprender Antropología el estudiante 
se ve enfrentado a su propia historia personal, llevándole incluso a cuestionar y poner en entredicho las verdades y certezas adquiridas en su entorno familiar y social más cercano. Este proceso de autoexploración, incluso de introspección, podrá conducir al autorreconocimiento de verdades, certezas y juicios que eventualmente pudiesen actuar como barreras ante el futuro ejercicio profesional. Al estar consciente de estas barreras personales, el futuro profesional podrá entonces desarrollar estrategias que le permitan neutralizarlas o clausurarlas, de modo tal, que el ejercicio profesional no se vea afectado por los valores y normas aplicables a la vida personal producto de la propia historicidad. Puesto que, si no lo hace, corre el riesgo de invisibilizar al Otro y, desde la posición de autoridad que da la profesión, excluirá toda posibilidad de actuación desde la ética de la alteridad.

Por ejemplo, Solana (2002), registra que trabajadores sociales que defendían posiciones asimilacionistas en el trabajo con inmigrantes, ejercieron presión para que abandonen su cultura de origen y se integren a la sociedad hegemónica, lo cual se considera un atentado al derecho a la diversidad cultural y contrario a la ética de la alteridad.

Por otra parte, el profesional en formación al reconocer que todo sujeto social con quien interactúa tiene una identidad cultural que lo hace ser etnocéntrico ha de estar dispuesto, si no atento, a comprender cuáles son los centrismos culturales que existen en los diversos niveles en que intervenga. Con ello, se verá favorecido el encuentro intersubjetivo tan necesario desde la perspectiva de alteridad.

Un tercer aporte conceptual que es fundamental para un profesional del Trabajo Social es el concepto de diversidad cultural. En tanto disciplina, la Antropología se caracteriza por su enfoque transcultural que, mediante la búsqueda de "similitudes y diferencias entre pueblos y comunidades (...) contribuye a descubrir la diversidad cultural y [a reconocer] que no existe un único modelo cultural" (Fernández, 2012, p.3-4). Desde que la Organización de Naciones Unidas para la Educación, la Ciencia y la Cultura (UNESCO) adoptó la declaración universal sobre la diversidad cultural, ésta es asumida como característica esencial del género humano que se expresa en una pluralidad de identidades y que, desde la perspectiva de los derechos humanos, "es un imperativo ético, inseparable del respeto de la dignidad de la persona humana" (UNESCO, 2010, p.281).

Al respecto, hace más de una década, Tello, Colangelo, Amilibia, Danel y Ducha (2005, 2017), iniciaron la reflexión acerca de cómo el desarrollo conceptual de la diversidad cultural contribuye a la comprensión de las desigualdades sociales a través de la identificación y reconocimiento de los simbolismos que encierra la vida social de los diversos grupos humanos con los que interactúan los trabajadores sociales cuando intervienen los contextos sociales, económicos, políticos y culturales. Desde esta visión, comprender los simbolismos (Geertz, 2003) y los campos sociales (Bourdieu, 1997) permite adentrase en el mundo social de las diversas colectividades que requieren de la intervención en miras a la transformación social (Amilibia et al., 2015). En este mismo orden de ideas, es fundamental que el 
trabajador social tenga la capacidad de reconocer los vínculos entre diversidad cultural y desigualdad social, pues en la cotidianidad de los sujetos sociales ambos constructos se encuentran en una permanente interacción: hay ocasiones en que la diferencia cultural genera desigualdades sociales, pero en otras, esa misma diferencia actúa como refugio o protección ante la desigualdad: "podemos encontrar actores sociales, colectivos sociales, que exaltan la diversidad como estrategia contra la desigualdad, y otros donde la diversidad busca ser limitada, controlada, si es posible ocultada, por considerarla fuente de desigualdad" (Milesi, 2012, p.5).

En la revisión de literatura sobre los aportes de la Antropología al Trabajo Social un aspecto vinculado al cambio cultural que ha sido escasamente abordado es la aculturación, concepto que ha suscitado latas discusiones antropológicas, pero que, para efectos de este trabajo, considera la clásica definición de los norteamericanos Redfield, Linton y Herkovits, quienes la refieren como el conjunto de fenómenos resultantes de que grupos de individuos pertenecientes a culturas distintas entren en contacto continuo y directo, con los subsiguientes cambios en las pautas culturales originales de uno o de ambos grupos (Spicer, 1979).

Entonces, ¿̇Qué aporta este concepto al Trabajo Social? En un mundo caracterizado, cada vez más, por los cambios de residencia y de territorios, por las movilidades geográficas y sociales, la modificación en las formas comunes de pensar, sentir y actuar es inevitable. Los contextos sociales donde interviene el profesional de Trabajo Social son multiculturales, con grupos culturales en interacción continua, donde los recién llegados vía migración o movilidad social se encuentran experimentando procesos de adecuación y adaptación, pues los grupos de referencia primarios han quedado atrás.

La intervención social debe ser pertinente en términos culturales y la aculturación demanda del profesional de Trabajo Social la comprensión del proceso aculturativo, tanto en sus causas como en los resultados a que puede conducir. La comprensión de la aculturación como una expresión de los procesos de cambio cultural abre una serie de temas de interés que en miras hacia la transformación social no pueden ser obviados. Ahí están, por ejemplo, el biculturalismo y las técnicas para dirigir el cambio, pues la Antropología permitirá comprender qué hace que algunos sujetos acepten dos o más formas de comportamiento y las pongan en práctica en contextos socioculturales distintos, así como hará también posible que la planeación de los asuntos sociales y su implementación se realice de cara a la gente y con la gente. La historia reciente de Chile como país receptor de población migrante representa un área de intervención para el Trabajo Social asociada a los efectos que produce la aculturación. Ésta tiene consecuencias tanto en la salud mental como en el bienestar social de los inmigrantes, ante lo cual el apoyo psicosocial y el trabajo en redes, desde el Trabajo Social, representan un abordaje efectivo para afrontar el estrés por aculturación. Asimismo, la experiencia relatada por Macedo, Martins y Troncarelli (2017) sobre una trabajadora social en la Casa de Apoyo a la Salud Indígena de Sao Paulo (Brasil) 
es particularmente ilustrativa de las funciones de mediación cultural en el tránsito entre el mundo indígena y el sistema médico estatal al que se ven expuestos nativos guaraníes que concurren por atención sanitaria.

\section{El método etnográfico}

Desde los planteamientos iniciales de Boas, a finales del siglo XIX, en cuanto que para comprender una cultura el trabajo de campo es un mal necesario, hasta los dichos de Malinowski en las primeras décadas del siglo XX sobre el hecho que "el ideal primordial y básico del trabajo etnográfico de campo es dar un esquema claro y coherente de la estructura social y destacar (...) las leyes y normas que todo fenómeno cultural conlleva" (1972, p.28), no hay dudas que el método etnográfico es una herramienta fundamental para la intervención social desde la lógica de la alteridad.

Hace décadas que la etnografía dejó de ser utilizada sólo por antropólogos; entre otros profesionales que recurren a ella están los trabajadores sociales (Restrepo, 2016), pues como ha sostenido Guber "el trabajo de campo etnográfico es el método (o mejor dicho, el conjunto de actitudes o disposiciones metodológicas) de las Ciencias Sociales que más se parece a la vida" (2005, p.1), ya que se sitúa en el nivel de la comprensión de los problemas asociados a la cotidianidad (Gómez, Rodríguez y Alarcón, 2005; Silva et al., 2015).

La idea que está en la base de todo trabajo de campo etnográfico es "que el/a investigador/a sólo puede conocer otros mundos sociales a través de su propia exposición a ellos" (Tello et al., 2017, p.22), transformando aquello que le resulta extraño en algo familiar o cercano. Situados en la acepción de la etnografía como enfoque (Guber, 2001), se hace posible el rescate de las voces alternativas de los sujetos intervenidos (Alcázar y Espinosa, 2014, p.345); en este nivel, la etnografía permite que el trabajador social comprenda la perspectiva del nativo, rescate las formas en que piensa, siente, hace y habla, es decir, se sitúe en los marcos de interpretación de la realidad que ocupan los sujetos en sus contextos naturales; mediante el encuentro intersubjetivo del trabajador social con el sujeto de intervención, desde el paradigma de alteridad se genera un "espacio de reconocimiento por el otro. Ahí sobresale un espacio de unicidad del otro que no es reductible" (Castro-Serrano et al., 2016, p.44).

La aproximación a ese mundo interior del nativo se realizará desde la etnografía como método, mediante el trabajo de campo y la puesta en escena de un conjunto de técnicas entre las que destacan la observación participante y la entrevista (Guber, 2001), aportando la información base para la descripción de la perspectiva nativa.

Ahora bien, la metodología etnográfica además de permitir la comprensión del mundo interior de los sujetos sociales también facilita intervenciones sociales más certeras (Gómez et al., 2005) y culturalmente pertinentes, pues: 
"Para realizar una adecuada intervención sobre las distintas realidades y en los diversos colectivos o en las comunidades, los profesionales de la intervención social deben conocer en profundidad los valores de las personas, las formas de entender su mundo, sentimientos y, en definitiva, su cultura". (Alcázar y Espinosa, 2014, p.345)

En fin, la metodología etnográfica es una invitación para que el profesional del Trabajo Social no naturalice las diversas formas de organización social (Petrelli, 2017) y se atreva a "averiguar cómo son las cosas allí donde toca intervenir y cómo es que los problemas llegan a merecer algún tipo de intervención" (Grassi, 2007, p.27). O, como Artiñano et al. (2017) indican, el método etnográfico representa una herramienta teórica y metodológica para el trabajador social, pues le permite generar conocimiento sobre una realidad social al mismo tiempo que realizar intervenciones sociales.

Trincheri et al. (2016) al comunicar una experiencia formativa con estudiantes de Trabajo Social, realizada entre los años 2012 y 2014, en una universidad argentina, concluye que la enseñanza del método etnográfico permite "involucrarse en ejercicios más sistemáticos y profundos de "descripción densa" y el despliegue de una sensibilidad etnográfica que posibilite nuevas maneras de interactuar y comprender las situaciones en que forjarán su intervención como trabajadores sociales" (p.62).

Ahora bien, recordando lo que se aprende al estudiar Antropología, no cabe duda de que el método etnográfico tributa a los tres tipos de aprendizajes identificados por Krotz (2012): aquellos vinculados al trabajo de campo, el desarrollo de habilidades intelectuales y científicas, y el desarrollo de competencias personales, pues:

"Estar ahí", observar hechos concretos, registrarlos. Correrse de generalidades basadas muchas veces en juicios previos o explicaciones abstractas. Dar lugar al extrañamiento, a la deconstrucción de estereotipos, a la desnaturalización de lo hasta entonces "conocido" y pensado. Ejercitar una escritura que emerja de las particularidades de las situaciones trabajadas para pensarlas en un "plano intermedio" son algunas de las características del método etnográfico". (Trincheri et al., 2016, p.62)

\section{Conclusión}

La pregunta que vertebra las páginas anteriores dice relación con lograr identificar cómo, a partir del paradigma de la alteridad, la Antropología realiza aportes conceptuales y metodológicos al Trabajo Social. Para ello, se han planteado algunos conceptos que atraviesan el quehacer antropológico desde sus inicios y referido la metodología etnográfica como estrategia distintiva del conocer y comprender antropológico, situados desde una reflexión sobre la alteridad y el otro en Trabajo Social.

Al concluir, la primera constatación será reconocer que el vínculo entre la Antropología y el Trabajo Social es una relación dinámica y flexible, en permanente construcción ética, conceptual y metodológica. 
Esta conclusión genera más aperturas que cierres, expresados en interrogantes que han de seguir pensándose y escribiéndose, dialogando en un espacio interdisciplinar. ¿̇ Hacia dónde se orientan los esfuerzos antropológicos en los procesos de formación en Trabajo Social? ¿̇Hacia trabajadores sociales generadores de conocimientos y saberes disciplinares? ¿Hacia profesionales competentes para la intervención social, abiertos hacia una relación y diálogo intersubjetivo a favor de un encuentro con el otro?

Con la alteridad los antropólogos han transitado desde lo exótico, primitivo e indígena hacia la complejidad del mundo globalizado. En el Trabajo Social ¿̇Quién es el otro en la actualidad? ¿ ¿ómo se construye ese otro en la intervención social?

En las primeras páginas de este artículo se estableció que el punto de partida de esta reflexión es la práctica docente y la escasez de producción académica nacional (en Chile) sobre los vínculos entre Antropología y Trabajo Social. Al respecto, se puede concluir en una serie de desafíos para la enseñanza-aprendizaje de Antropología a profesionales en formación del Trabajo Social, que recaen en el antropólogo que pretende facilitar aprendizajes. Una de ellas es la necesidad de conocer y comprender las historicidades y contextualidades del Trabajo Social; no se puede enseñar Antropología a trabajadores sociales sin conocer sobre Trabajo Social. Aquí aplica en plenitud la alteridad.

Así también, el antropólogo que transmite saberes antropológicos a trabajadores sociales en formación ha de tener la capacidad de lograr transposiciones didácticas adecuadas, claras y pertinentes al contexto del estudiantado. He aquí otra expresión de alteridad.

\section{Bibliografía}

Alcázar, A. y Espinosa, M. (2014). ¿Por qué es importante la etnografía para el Trabajo Social? Algunas reflexiones para el debate. Humanismo y Trabajo Social, 13-14, 335-347.

Amilibia, I. (2017). Enseñanza de Antropología e interdisciplina. En C. Tello (coord.), Antropología e intervención social desde la formación en Trabajo Social. (pp.35-52). La Plata, Argentina: Universidad Nacional de La Plata.

Amilibia, I., Colangelo, M., Danel, P., Rodríguez, P. y Tello, C. (noviembre-diciembre de 2015). La Antropología social en la formación de trabajadores sociales. Reflexiones desde una experiencia de cátedra. XI Reunión de Antropología del Mercosur, Montevideo. Uruguay.

Artiñano, N., Bergé, E., García, M. y Gómez, M. (2017). Desafíos de la enseñanza de la etnografía. Reflexiones desde la Antropología en relación a la formación de los/las trabajadores/as sociales (FTS, UNLP). Recuperado de: http:// sedici.unlp.edu.ar/handle/10915/64339

Baldoni, C. y Fontana, J. (2016). Encuentros con la alteridad. Hacia modalidades otras del Trabajo Social. Recuperado de: http://sedici.unlp.edu.ar/handle/10915/64374

Barahona, M.J. (2016). El Trabajo Social: una disciplina y profesión a la luz de la historia. Madrid, España: Universidad Complutense de Madrid.

Bourdieu, P. (1997). Razones prácticas. Sobre la teoría de la acción. Barcelona, España: Editorial Anagrama.

Bourdieu, P. y Wacquant, L. (1995). Respuestas. Por una Antropología reflexiva. 
México D.F., México: Grijalbo.

Brunatti, O. et al. (abril de 2016). Enseñando el oficio antropológico: prácticas preprofesionales en la materia Antropología Sociocultural II. En Universidad Nacional de La Plata. (2017). Memorias de las $1^{a}$ jornadas sobre las prácticas docentes en la universidad pública: transformaciones actuales y desafíos para los procesos de formación, La Plata, Argentina.

Carballeda, A. (2008). Los cuerpos fragmentados. La intervención en lo social en los escenarios de la exclusión y el desencanto. Buenos Aires, Argentina: Paidós.

Castro-Serrano, B., Reininger, T., Flotts, M., Vergara, M. y Fuentealba, A. (2016). Transferencias monetarias condicionadas y pobreza: Trabajo Social y su intervención en perspectiva de alteridad. Intervención, (6), 38-45.

Cerletti, L. (2017). Antropología y educación en Argentina: de condiciones de posibilidad, preocupaciones en común y nuevas apuestas. Horizontes Antropológicos, 23(49), 123-148. doi: 10.1590/S0104-71832017000300005

Chiriguini, M. y Mancusi, M. (2008). Apertura a la Antropología: alteridad, cultura, naturaleza humana. Buenos Aires, Argentina: Proyecto Editorial.

Conti, L. (2012). Interkultureller dialog im virtuellen zeitalter. Neve perspektive fur theorie und praxis. Munster, Deutschland: Lit Verlag.

Cruz, M., Ortiz, M., Yantalema, F. y Orozco, P. (2018). Relativismo cultural, etnocentrismo e interculturalidad en la educación y la sociedad en general. Academo, 5(2), 179-188. doi: 10.30545/academo.2018.jul-dic.10

Domingo, A. (2013). Práctica reflexiva para docentes. De la reflexión ocasional a la reflexión metodológica. Saarbrücken, Alemania: Publicia.

Farías, F. (2012). El Trabajo Social y los campos disciplinarios de las Ciencias Sociales en Chile. Cinta Moebio, (43), 50-60.

Fabrizio, M. y Gallardo, S. (2016). "¿A quiénes les enseñamos y qué contenidos elegimos...? Repensando la contextualización y la producción de conocimiento en el aula desde - y para - la enseñanza de la Antropología. REBES. Revista Brasileira de Ensino Superior, 2(1), 8-20. doi: 10.18256/2447-3944/rebes. v2n $1 \mathrm{p} 8-20$

Fernández, I. (2012). Introducción. Aportaciones de la Antropología al Trabajo Social. España: Universidad del País Vasco.

Fombuena-Valero, J. (2011). ¿Quién es el otro del Trabajo Social? Alteridad y Trabajo Social. Portularia, XI (2), 61-68. doi: 10.5218/prts.2011.0018

Geertz, C. (2003). La interpretación de las culturas. Barcelona, España: Gedisa Editorial.

Gallego, C. (2000). Antropología aplicada y Trabajo Social. Acciones e Investigaciones Sociales, (10), 5-22.

Gómez, I., Rodríguez, L. y Alarcón, L. (2005). Método etnográfico y Trabajo Social: algunos aportes para las áreas de investigación e intervención social. Fermentum. Revista Venezolana de Sociología y Antropología, 15(44), 353-366.

Grassi, E. (2007). Problemas de realismo y teoricismo en la investigación social y en el Trabajo Social. Revista Katálysis, 10(n.esp.), 26-36.

Guber, R. (2001). La etnografía. Método, campo y reflexividad. Bogotá, Colombia: Grupo Editorial Norma.

(2005). El salvaje metropolitano. Buenos Aires, Argentina: Editorial Paidós.

Harris, M. (1996). Antropología cultural. Madrid, España: Alianza Editorial.

Idareta, E. (2011). De Mary Richmond a Karl R. Popper y Emmanuel Lévinas: hacia la cientificidad y el conocimiento ético para el Trabajo Social. Cuadernos de Trabajo Social, (24), 85-99. doi: 10.5209/rev_CUTS. 2011 .v24.36860

Krotz, E. (1994). Alteridad y pregunta antropológica. En M. Boivin, A. Rosato y V. Arribas (coord.). (1999). Constructores de otredad. Una introducción a la Antropología social y cultural (pp. 16-21). Buenos Aires, Argentina: Eudeba.

.(2012). ¿Qué se aprende cuando se estudia Antropología? Estudios en Antropología Social - CAS/IDES, 2(1), 3-14.

Larraín, J. (2014). Identidad chilena. Santiago, Chile: LOM Ediciones.

Lévi-Strauss, C. (1995). Antropología estructural. Barcelona, España: Paidós.

Linton, R. (1971). Cultura y personalidad. Ciudad de México, México: Fondo de Cultura Económica.

Macedo, V., Martins, J. y Troncarelli, M. (2017). Três linhas e alguns nós: serviço social, educação e antropologia na CASAI-SP. Amazôn. Revista de Antropo- 
logia, (Online) 9(2), 632 - 659. doi: 10.18542/amazonica.v9i2.5668

Malinowski, B. (1972). Los argonautas del Pacífico Occidental. Barcelona, España: Ediciones Península.

Mancera, F. y Romero, R. (2017). Enseñanza y aprendizaje en la Antropología de contextos interculturales de la sierra Tarahumara. Revista de Investigación Educativa de la REDIECH, 7(13), 58-73.

Mijangos, J. y Ambrocio, I. (2013). Alfabetización académica: escritura y lectura en la enseñanza de Antropología de la educación. Revista Panamericana de Pedagogía. Saberes y Quehaceres del Pedagogo, (20), 35-58.

Milesi, A. (septiembre de 2012). Diversidad y desigualdad: contribuciones de la Antropología para el Trabajo Social. XX Seminario Latinoamericano de Escuelas de Trabajo Social. Córdoba, Argentina.

Ortale, M. (2018). La enseñanza de Antropología cultural y social: propuestas, derivas, reconocimientos y desafíos. Trayectorias Universitarias, 4(7), 45-52.

Ortiz, A. (2016). La enseñanza de la Antropología en el sistema educativo: retos y desafíos actuales. Revista de Humanidades y Ciencias Sociales, 7 (2) 39-45.

País, M., Girola, M. y Thomasz A. (2016). Interpelando el Trabajo Social desde la Antropología: nuevas "demandas" de conocimiento para reflexionar e intervenir en el espacio de lo público. Reflexiones a partir de una experiencia pedagógica. Recuperado de: http://trabajosocial.sociales.uba.ar/wp-content/ uploads/sites/13/2016/03/50.pdf

Petrelli, L. (2017). Relacionarse, conocer e intervenir: reflexiones sobre los aportes de la perspectiva antropológica al desarrollo del Trabajo Social. TS. Territorios. Revista de Trabajo Social, 1(1), 75-90.

Raya-Diez, E., Ezquerro, M. y Serrano-Martínez, C. (2019). Gestión de la diversidad cultural: recursos y herramientas del Trabajo Social. Comunitania, (18), 65-84.

Restrepo, E. (2016). Etnografía: alcances, técnicas y éticas. Bogotá, Colombia: Envión Editores.

Sepúlveda, C. (noviembre de 2001). Aportes de la Antropología a la reforma educativa: la comprensión lectora como estrategia y el título como herramienta reveladora del contenido de la interpretación. IV Congreso Chileno de Antropología, Santiago de Chile.

Silva, P.., Sacramento, O., y Mendonça, V. (2015). Proximidade, reflexividade e crítica: o lugar da etnografia na intervenção social. Cuadernos de Trabajo Social, 28(1), 27-37. doi: 10.5209/rev_CUTS.2015.v28.n1.46678

Solana, J. (2002). La dimensión cultural en el Trabajo Social con población inmigrante (una perspectiva desde la Antropología social). Portularia, (2), 139155.

Spicer, E. (1979). Aculturación. Enciclopedia Internacional de las Ciencias Sociales. Madrid, España: Aguilar.

Tello, C., Colangelo, M., Amilibia, I., Danel, P. y Ducha, M. (agosto de 2005). Aportes de la mirada antropológica a la formación del trabajador social. Trabajo presentado en el Encuentro Latinoamericano de Trabajo Social "La formación y la intervención profesional en la sociedad contemporánea. Hacia la construcción de un proyecto ético-político", Escuela Superior de trabajo Social, Universidad Nacional de La Plata.

Tello, C. et al. (2017). La mirada antropológica en la formación del/de la trabajador/a social. En C. Tello (coord..), Antropología e intervención desde la formación en Trabajo Social (pp.16-25). La Plata, Argentina: Universidad Nacional de La Plata.

Todorov, T. (1998). La conquista de América. El problema del otro. México D.F., México: Siglo Veintiuno Editores.

Trincheri, M. et al. (2016). La observación y descripción barrial en la formación de la/os trabajadora/es sociales. Trayectorias Universitarias, 2(3), 56-63.

UNESCO. (2010). Declaración Universal de la UNESCO sobre la diversidad cultural. Praxis, (64-65), 279-284.

Zárate, P. (2016). Reconocimiento y alteridad en la relación Trabajo Social y persona humana: una senda a partir de la Antropología filosófica. Revista Perspectivas, (28), 163-179. 